\title{
Is there a role for publication consultants and how should their contribution be recognized?
}

September 26, 2015

\section{Abstract}

When a scientific paper, dissertation or thesis is published the author(s) have a duty to report who has contributed to the work. This recognition can take several forms such as authorship, relevant acknowledgments and by citing previous work. There is a growing industry where publication consultants will work with authors, research groups or even institutions to help get their work published, or help submit their dissertation/thesis. This help can range from proof reading, data collection, analysis (including statistics), helping with the literature review and identifying suitable journals/conferences. In this opinion article we question whether these external services are required, given that institutions should provide this support and that experienced researchers should be qualified to carry out these activities. If these services are used, we argue that their use should at least be made transparent either by the consultant being an author on the paper, or by being acknowledged on the paper, dissertation or thesis. We also argue that publication consultants should provide an annual return that details the papers, dissertations and thesis that they have consulted on.

Keywords: Ethics, Agency, Consultant, Research Misconduct, Transparency

\section{Introduction}

Publishing in the scientific literature requires the authors to observe the highest levels of ethical integrity, including acknowledging who has contributed to the work. Being an author is the most obvious way of indicating a contribution. Once the list of authors has been established, it is their responsibility to ensure that other contributions are also noted. This is usually done via the acknowledgments section where a contribution, that does not merit authorship, is recognized. A further way to recognize a contribution is by citing previous work. If we are going to "Stand on the shoulders of giants", we should recognize the shoulders that we are standing upon. 
This is not only for the benefit of the scientific community, but also to the benefit of the general public who have the right to expect that scientific research is being carried out in a rigorous, transparent and reproducible manner. There are many areas where it is clear what is expected of scientists. There is no defense, for example, for plagiarizing the work of others or fabricating results. There are also guidelines as to what constitutes a contribution to a paper and whether a given person should be an author or simply acknowledged (Wager and Kleinert, 2011).

Anybody who has a $\mathrm{PhD}$, or is working towards a $\mathrm{PhD}$, should be aware of what is expected of them as a scientist. Whether an author is an experienced or an early career researcher, they have to recognize their responsibility to publish in an ethical way. Indeed, anybody who has studied at a university, whether holding a $\mathrm{PhD}$ or not, has very little excuse if they step over the line of accepted practice when they submit their work for peer review. Ignorance cannot be used as a defense. The same standards equally apply to researchers who work within research institutes, R\&D departments or even just individuals who have no affiliation with a university or company. The responsibility lies with the author(s) that they respect the ethics of publishing.

Researchers also have a responsibility to their institution/company in ensuring that they do not damage its reputation by the actions of a single person, or a group of authors.

Aside from the support provided by institutions, there is a lot of information for scientific authors in case there is any confusion about accepted practise. Many books (e.g. Booth et al. (2003), Philips and Pugh (2006)) cover the ethics of publishing, journals/conferences will provide information on what they expect from their authors and many scientists write blogs that cover the ethics of publishing.

Moreover, initiatives such as Good Laboratory Practice (GLP) provides guidance on research ethics. GLP was established in non-clinical research over 40 years ago to monitor the safety or efficacy of chemicals. GLP manages the quality of research laboratories and organizations, ensuring their uniformity, consistency, reliability, reproducibility, quality, and integrity. GLP was established after four scientists were put on trial after faking drugs and chemical studies in the 1970's ((Anon, 1983)). New Zealand and Denmark introduced GLP in 1972, followed by the USA in 1978. OECD (Organization for Economic Co-operation and Development) (OECD) adopted the principles in 1992 and has promoted them ever since.

Even so, there are still some issues around reproducibility. Begley and Ellis (2012) have recently suggested that pre-clinical standards need to be raised in cancer research. They report that only $25 \%$ of pre-clinical trials could be validated. Baker (2012) reports that some publishers are supporting an initiative where high profile authors have the results verified by an independent laboratory. Prinz et al. (2011) notes that many pharmaceutical companies have validation programmes before making an investment, but they often find that results in a scientific paper are difficult to reproduce.

Recently, GLP has been proposed for Optimization Research (Kendall et al., 
in press). Two of the recommendations state "Researchers should adopt the highest ethical standards in conducting their research" and "Researchers should ensure that the work of others is properly cited", which supports the arguments made in this paper. Kendall et al. (in press) contains 54 recommendations for the optimization community.

A further example of good practice is the Committee on Publication Ethics (COPE). This was established in 1997 and its members includes many of the major publishers. Its web site explains the role of COPE:

"COPE ${ }^{1}$ provides advice to editors and publishers on all aspects of publication ethics and, in particular, how to handle cases of research and publication misconduct. It also provides a forum for its members to discuss individual cases. COPE does not investigate individual cases but encourages editors to ensure that cases are investigated by the appropriate authorities (usually a research institution or employer)."

Both GLP and COPE provide guidance as to what is expected with regard to research ethics, as well as providing support in other areas, such as reproducibility etc.

In this opinion article we highlight an area which we believe is neglected at the present time, and is not covered by current standards or guidelines. This has the potential for the scientific community not to be fully informed about a piece of peer reviewed work, leading to uncertainty as to whether the work is solely that of the authors. In our view, the scientific community should address this issue, so that it is fully transparent as to who has contributed to a given piece of work.

We encourage institutions to openly state whether they support, financially or otherwise, their staff/students utilizing publication consultants. We also encourage editors and publishers to make it a requirement that authors openly state whether they have utilized a publication consultant and, if so, what type of support was given and how much it cost.

In our view, post-doctoral staff should have the required expertise to publish without external support and they should also be able to supervise students, without having to access external expertise.

\section{Publication Consultancy}

There are services being advertised that will assist authors in getting their work published. We do not name any particular service in this article as we do not want to draw attention to any particular company, but rather discuss the generic issue. Therefore, the comments below are drawn from a variety of service providers and represents a general overview of this industry, rather than focusing on any one provider.

\footnotetext{
${ }^{1}$ http://publicationethics.org/
} 
Many services offer a proof reading and/or editing service. In our view, this is acceptable. Many article reviewers will comment on the level of English and suggest that the article is acceptable for publication but it should be proof read by a native English speaker. Using a paid service to proof read the article may be the only way that the authors can get the English/grammar to an acceptable level. What is important is that the proof reader is solely correcting the English/grammar and making no technical changes to the article. Indeed, if anything is unclear, it should be referred back to the authors for clarification.

If an English language editing service has been used, this should be noted in the acknowledgments for the paper, dissertation or thesis.

We note that the correction of English for a student dissertation/thesis (or even a paper written by a student), via a paid service, is more difficult to justify. The student has registered, in good faith, at the university and is often paying significant fees. They may have also had to pass an English language examination and the university has registered the student, being satisfied that they have a good enough level of English to undertake the course. The university has a duty of care to their students and should provide adequate support to ensure that a dissertation/thesis/paper is written to the level of English/grammar that it expects from its students, without expecting them to use an additional service for which they have to pay.

Some publication consultants are members of COPE and subscribe to policies in areas such as plagiarism. Some even have a link to a few of the articles that they have helped with, but certainly not full disclosure. Some also highlight that confidentiality is of prime importance. This, we believe, relates to the confidentiality of the research being presented (which should be applauded) but also relates to respecting the confidentiality of the authors who use the service.

Services beyond proof reading, in our view, are more dubious. Below we provide a few examples, not a comprehensive list, of the type of services that are being offered by publication consultants. Although we quote the text, none of it has been directly copied from any one service provider but is just representative of the range of services that are offered. We provide a brief comment on each.

1. "Assist PhD students publish their articles and papers in leading journals to international standards"

Comment: PhD students will be registered at a university and will be appointed a supervisor. The university/supervisor have a duty of care to the students both in terms of training and supporting them and also in helping them develop their career so that they can become an independent researcher. It is unclear why a student should seek external support, when their university should be supporting them and providing the necessary instruction/training/practice in the production of a paper in (typically) English.

If the paper is subsequently published, it is not currently accepted practice to acknowledge the help of an external consultant. This misleads the scientific community as they are not informed about who has helped with some aspects of the paper. 
2. "Help in all stages of their research, including data collection, methodology, statistical analysis and academic publications"

Comment: If a researcher is helped by an external agency in these important areas, is it really their own work? Do the authors understand the methodology, results and analysis?

Indeed, it might be argued that the publication consultants are actually making the main contribution perhaps, more so, than the listed authors. Given that the publication consultant is not even acknowledged, this would be a misrepresentation of the contribution being made. Only full disclosure of the contribution of the publication consultant would enable editors, reviewers and readers to make a reasoned judgment.

If the same support was given by an academic colleague from your own institution, there may be a case for them to be an author on the paper. At a minimum, their help should be acknowledged in the appropriate section.

3. "Assistance in statistical analysis via tools such as SPSS"

Comment: If you are a $\mathrm{PhD}$ student then surely you want to learn how to use these analysis tools, rather than give your data to a third party who will do the interpretation and/or analysis. Even if the third party only helps with the presentation, it should be the responsibility of the authors to present their work in the correct way. Similar to point 1 , the supervisor/university also has a duty to the student rather than seeking outside assistance.

If you are a post-doctoral researcher, then you should be able to carry out the analysis yourself, or collaborate with somebody who can, and acknowledge them appropriately.

4. "Help in selecting where to publish"

Comment: Part of doing a $\mathrm{PhD}$ (and post-doctoral work) is having an overview of the literature, knowing the key journals/conferences in your area, and deciding where to publish. If you are entering into a new research area, your training should enable you to find out where other researchers are publishing.

5. "Extracting and publication of papers from a thesis"

Comment: Surely, this is the job of the student and/or the supervisor(s). It could be argued that the research has been done and writing the paper is purely a mechanical process and does not add to the contribution that the research is making. We would argue that it is not simply a case of extracting from the thesis, but the literature review has to be put into the context of the paper (and perhaps updated), the analysis might need further refinement, the paper has to be written for the targeted journal/conference etc. This is surely the responsibility of the authors and cannot (should not) be contracted out.

If researchers are using publication consultants, and not declaring their contribution, then they are misrepresenting themselves to the academic community. 
If somebody applies for promotion, or a new position in another institution, should they declare that they received external assistance for a given paper, dissertation or thesis? Our view is yes, and we also believe that this should be apparent to anybody reading the paper, dissertation or thesis, not just provided upon request.

If the publication consultant has made a contribution to the paper then they should be listed as an author on the paper. If it is felt that the help does not warrant the person being an author then the publication consultant should be acknowledged, and in a way that makes it clear what their role was, and what activities they undertook.

\section{Recommendations}

In this section we make a number of recommendations. We believe that if these are adopted then the role of publication consultants, if they are used, would be a lot more transparent.

1. If help has been provided by a publication consultant, this must be declared in the paper, dissertation or thesis. This should be in the form of an acknowledgment, unless the work carried out justifies that the consultant should be an author.

2. If there is any doubt whether the work of a publication consultant should be acknowledged, the authors should seek advice from the journal/conference to which they are submitting, although we would suggest that a declaration should be made if there is any doubt.

3. The use of a publication consultant should always be acknowledged, even if the author is writing as an independent, single author.

4. The exact nature of the support received should be clearly stated so that it is clear to the readers which parts of the paper were written with assistance.

5. If the consultant has only read/corrected the paper from an English/grammatical point of view, it should be noted that the consultant only proof read the paper and made no other contribution.

6. The name of the consultant (company and individual) should be stated.

7. The amount paid to the publication consultants should be stated. This provides some measure of the magnitude of the assistance that was provided.

8. An acknowledgment that a publication consultant was used is made on behalf of all the authors, recognizing that they all have a joint responsibility for the paper. 
9. If the publication consultant contributes in a way that would normally warrant being an author, then the consultant should be listed as an author.

10. Journals/conferences should require a statement from authors, at the time of article submission, as to whether they have used a publication consultancy service, in a similar way you need to declare that the work has not been submitted elsewhere or that the work is your own work.

If a later version of the paper utilizes a publication consultation service, which was not the case for previous versions, this should be declared to the journal/conference editors, the reviewers and acknowledged on the revised paper.

11. Journals and publishers should require authors to acknowledge any help they have received from publication consultants.

12. Universities, other institutions of higher learning, research institutes, $R \& D$ departments etc. should have a policy as to whether they support, financially or otherwise, the use of publication consultants and, if they do support their use, they should state that they require researchers writing under their affiliation to acknowledge the help that they received.

13. Universities, other institutions of higher learning, research institutes, $R \& D$ departments etc. should state whether their staff/students can expect support from within the organization and/or whether their training should have prepared their staff/students to be able to publish without the assistance of publication consultants.

14. Any company/individual who provides publication consultancy should be required to prepare an annual return, specifying any papers, dissertations or thesis that they have helped with over the previous 12 months. This return could either be to a central repository and/or made to the publisher(s) of the papers they have been assigned.

15. Journals, in particular, should print annually a list of the papers that have been published with the assistance of a publication consultant, in the same way that reviewers are often acknowledged each year.

\section{Concluding Remarks}

Given the publish or perish environment in which academics live, it is not surprising that publication consultancy services have sprung up. As a proof reading service, this is acceptable and welcomed. Supervised students should be the exception, as they should get support from their institution. The worrying trend is that publication consultants may be carrying out activities which a reader might reasonably assume that one of the authors had done.

There are three main reasons why we feel that the recommendations in this article should be adopted: 
1. When you read a scientific article you have the right to expect that the work it represents was carried out by the authors. Any assistance the authors received (perhaps in the form of research funding) should be recognized in the acknowledgments section. This also applies to publication

consultants. Any help received should be fully acknowledged and, if the contribution warrants it, the consultant should be listed as an author on the paper

2. It is questionable as to why institutions/authors need the services of publication consultants? Post-doctoral students/staff, by definition, should be trained in how to undertake research. Students are registered at an institution and have a supervisor. Should additional support be required? In our view they should not.

3. Implementing the recommendations in this opinion article would highlight who is having to use a paid service to get the help that they believe they need, and would highlight those institutions that do not provide this support to its staff/students.

Readers of academic papers have the right to know who contributed to the paper, whether this is by the list of authors, by the acknowledgments or by the work that is cited. Any help, not represented by the list of authors, should be acknowledged. This is often done by recognizing the funding agency, the efforts of colleagues, software providers etc. This acknowledgment should also extend to publication consultancy services, where assistance has been provided, albeit via a paid for service.

\section{References}

Anon. 1983. The Murky World of Toxicity Testing. Science 220(4602) 11301132. doi:10.1126/science.6857237.

Baker, M. 2012. Independent labs to verify high-profile papers: Reproducibility initiative aims to speed up preclinical research. Nature (News), 14 Aug 2012 doi:10.1038/nature.2012.11176.

Begley, C. G., L. M. Ellis. 2012. Drug development: Raise standards for preclinical cancer research. Nature 483(7391) 531-533. doi:10.1038/483531a.

Booth, W.C., G.G. Colomb, J.M. Williams. 2003. The Craft of Research. 2nd ed. The University of Chicago Press.

Kendall, G., R. Bai, J. Błazewicz, P. De Causmaecker, M. Gendreau, R. John, J. Li, B. McCollum, E. Pesch, R. Qu, N. Sabar, G. Vanden Berghe, A. Yee. in press. Good Laboratory Practice for Optimization Research. Journal of the Operational Research Society . 
Philips, M., D.S. Pugh. 2006. How to get a PhD: A Handbook for Students and their Supervisors. 4th ed. Open University Press.

Prinz, F., T. Schlange, K. Asadullah. 2011. Believe it or not: how much can we rely on published data on potential drug targets? Nature Reviews Drug Discovery 10(7391) 10-11. doi:10.1038/nrd3439-c1.

Wager, E., S. Kleinert. 2011. Promoting Research Integrity in a Global Environment, chap. Responsible Research Publication: International Standards for Authors: A position statement developed at the 2nd World Conference on Research Integrity, Singapore, July 22-24, 2010. Imperial College Press / World Scientific Publishing, 309-316. Available from http://bit.ly/1VM7rGQ (last accessed 26 Sep 2015). 